\title{
Exploration of the exonic variations of the iPSC-related Nanog gene and their effects on phenotypic traits in cattle
}

\author{
Meng Zhang, Chuanying Pan, Qin Lin, Shenrong Hu, Ruihua Dang, Chuzhao Lei, Hong Chen, and \\ Xianyong Lan
}

College of Animal Science and Technology, Northwest A\&F University, Shaanxi Key Laboratory of Molecular Biology for Agriculture, Yangling, 712100 Shaanxi, China

Correspondence to: Xianyong Lan (lan342@126.com) and Hong Chen (chenhong1212@126.com)

Received: 26 April 2016 - Revised: 19 July 2016 - Accepted: 26 July 2016 - Published: 11 August 2016

\begin{abstract}
Nanog is an important pluripotent transcription regulator transforming somatic cells to induced pluripotent stem cells (iPSCs), and its overexpression leads to a high expression of the growth and differentiation factor 3 (GDF3), which affects animal growth traits. Therefore, the aim of this study was to explore the genetic variations within the Nanog gene and their effects on phenotypic traits in cattle. Six novel exonic single nucleotide polymorphisms (SNPs) were found in six cattle breeds. Seven haplotypes were analyzed: TCAACC $(0.260)$, TCAATA $(0.039)$, TCATCC $(0.019)$, TCGACC $(0.506)$, TCGATA $(0.137)$, TCGTCC (0.036), and CTGATA (0.003). There were strong linkage disequilibriums of SNP1 and SNP2 in Jiaxian cattle as well as of SNP5 and SNP6 in both Jiaxian cattle and Nanyang cattle. Moreover, SNP3, SNP4, and SNP5 were associated with phenotypes. The individuals with GG genotype at the SNP3 locus or AA genotype at the SNP4 locus showed better body slanting length and chest circumference or body height and hucklebone width in Nanyang cattle. The superiority of the SNP5-C allele regarding body height and cannon circumference was observed in Jiaxian cattle. The combination of SNP3 and SNP4 (GG-AA) had positive effects on body height, body slanting length, and chest circumference. These findings may indicate that Nanog, as a regulator of bovine growth traits, could be a candidate gene for marker-assisted selection (MAS) in breeding and genetics in cattle.
\end{abstract}

\section{Introduction}

Induced pluripotent stem cells (iPSCs), derived from transcription-factor reprogramming, redefine our ability to develop the protein production of livestock, to improve disease resistance and production efficiencies, and to develop modeled livestock for research (Liang and Zhang, 2013; Lei el al., 2013). iPSCs are generated directly interacting with Nanog, Klf4, Oct4, Sox2, C-Myc, and other transcription factors. Among them, the iPSC-related transcription factor Klf4 is necessary for adipose differentiation and development (Cervantes-Camacho et al., 2015). Similarly, Klf7 regulated energy metabolism and affected bovine growth (Ma et al., 2011). Thus, another iPSC-related transcription factor Nanog was inferred to affect growth traits in cattle.
As a vital member of iPSC-related genes, Nanog, which consists of four exons and three introns in different species, is conservative and blocks the differentiation of pluripotent stem cells (Clark et al., 2004; Sumer et al., 2011). In a comparison and analysis of human, murine, and bovine Nanog promoter sequences, the promoters contained highly conserved regions (Rodda et al., 2005). In primordial germ cells (PGCs), Nanog was required for germ cell development (Yang et al., 2015). Recently, Nanog overexpression promoted the expression of the growth and differentiation factor 3 (GDF3), which is a member of the transforming growth factor beta (TGF- $\beta$ ) family (Park et al., 2012). TGF- $\beta$ affects differentiation processes during embryonic development and regulates bone formation as well as bone resorption (Shi et al., 2016; McPherron and Lee, 1993). GDF3 is expressed in bone marrow, thymus, spleen, and fat and exhibits a particu- 
Table 1. Primers used for detecting mutations of Nanog gene in cattle

\begin{tabular}{|c|c|c|c|c|}
\hline Primer & Primer sequence $\left(5^{\prime}-3^{\prime}\right)$ & Product size (bp) & $T_{\mathrm{m}}\left({ }^{\circ} \mathrm{C}\right)$ & Target region \\
\hline \multirow[t]{2}{*}{ P1 } & F: ТTТCСТТСТССТТСААСТCA & 169 & 55.5 & Exon 1 \\
\hline & R: TGTGCCTGTGACCATTCTTT & & & \\
\hline \multirow[t]{2}{*}{ P2 } & F: СТССТСТТСССТССТСC & 274 & 50.0 & Exon 2 \\
\hline & R: GATGTTCGTCCATGTCAACAA & & & \\
\hline \multirow[t]{2}{*}{ P3 } & F: TTTTCCGGTTATCTTTTC & 113 & 48.4 & Exon 3 \\
\hline & R: CCTTATCGTTACCGTAC & & & \\
\hline \multirow[t]{2}{*}{ P4 } & F: TCAGTTAATCCATTCTTCTTT & 473 & 49.3 & Exon 4 \\
\hline & R: AACACTGCCGATAACATAC & & & \\
\hline
\end{tabular}

larly high level of expression in white-fat tissue in mice; this was mainly induced by a high-fat diet and blocking of the fat metabolic pathway (Wang et al., 2004). The presence of Nanog inhibits the transcriptional effectors of both the bone morphogenetic protein and NF-kappa B pathways in embryonic stem cells (ESCs) (Li et al., 2016). Moreover, GLI1 and GLI3 bind to Nanog, but Nanog inhibits GLI transcription and Hedgehog signaling (Li et al., 2016). These proteins and pathways influence the physiological function development of cells and organisms.

The experimental animals used in this study are excellent cattle breeds from different Chinese locations. Qinchuan cattle (QC), Nanyang cattle (NY), Jiaxian cattle (JX), and Jinnan cattle $(\mathrm{JN})$ are the major meat-producing cattle; Angus $(\mathrm{AN})$ and Chinese Holstein $(\mathrm{CH})$ have been introduced from abroad. Based on the previous reports, this study explored the effects of SNPs in the Nanog gene on the growth traits of these cattle, which would contribute to cattle breeding and genetics through marker-assisted selection (MAS).

\section{Materials and methods}

All animal experiments were implemented following relevant laws and institutional guidelines and were approved by the Northwest A\&F University Institutional Animal Care and Use Committee.

\subsection{DNA samples}

A total of 796 cattle belonging to six Chinese breeds were used for this experiment, including Nanyang $(n=247)$, Qinchuan ( $n=144)$, Jiaxian $(n=269)$, Jinnan $(n=28)$, Angus $(n=47)$, and Chinese Holstein $(n=61)$. All selected individuals were healthy and unrelated. Records of growth traits and body sizes for different growth periods (postnatal and $6,12,18$, and 24 months old) were collected for statistical analysis (Pan et al., 2008). Ear tissue and blood samples of individuals were obtained and stored at $-80^{\circ} \mathrm{C}$ for DNA isolation. Genomic DNA was isolated from ear tissue and leukocytes from blood samples according to the procedure described by Sambrook and Russell (2001) and stored at $-20^{\circ} \mathrm{C}$.

\subsection{PCR conditions and genotyping}

Four pairs of primer were designed for the Nanog gene by the Primer Premier 5.0 program (Table 1), covering exons 1-4 based on the available sequence of the bovine Nanog gene (GeneBank accession No. AC_000162.1). PCR (polymerase chain reaction) was performed in a $25 \mu \mathrm{L}$ reaction volume, containing $50 \mathrm{ng}$ genomic DNA, $0.5 \mu \mathrm{mol} \mathrm{L}^{-1}$ of each primer, $1 \times$ buffer (including $1.5 \mathrm{mmol} \mathrm{L}^{-1} \mathrm{MgCl}_{2}$ ), $200 \mu \mathrm{mol} \mathrm{L}^{-1} \mathrm{dNTPs}$, and 0.625 unit of TaqDNA polymerase (MBI, Vilnius, Lithuania). The PCR amplification conditions were as follows: initial denaturing at $95^{\circ} \mathrm{C}$ for $5 \mathrm{~min}$ followed by 36 cycles of $95^{\circ} \mathrm{C}$ for $30 \mathrm{~s}$, annealing $30 \mathrm{~s}$, and extending at $72{ }^{\circ} \mathrm{C}$ for $30 \mathrm{~s}$, with a final extension at $72{ }^{\circ} \mathrm{C}$ for $10 \mathrm{~min}$ (Lan et al., 2007).

Aliquots of $5 \mu \mathrm{L}$ PCR products from different individuals were mixed with $5 \mu \mathrm{L}$ denaturing solution (95\% formamide, $25 \mathrm{mM}$ EDTA, $0.025 \%$ Xylene cyanole, and $0.025 \%$ bromophenol blue), heated for $10 \mathrm{~min}$ at $98^{\circ} \mathrm{C}$, and chilled on ice. Denatured DNA was subjected to PAGE (polyacrylamide gel electrophoresis) $(80 \times 73 \times 0.75 \mathrm{~mm})$ in $1 \times$ TBE buffer at constant voltage $(200 \mathrm{~V})$ for $2.5-3.0 \mathrm{~h}$. The gel was stained with $0.1 \%$ silver nitrate (Lan et al., 2007). The bands of products on PAGE gels were distinguished and selected for purification and sequencing. Comparing sequencings, we confirmed that two polymorphisms existed in the first exon, one polymorphism in the second exon, and three polymorphisms in the fourth exon in the Nanog gene (Fig. 1). To check the result of SSCP (single-stranded conformational polymorphism), we carried out PCR-RFLP (polymerase chain reaction restriction fragment length polymorphism) on SNP1 and SNP5. Aliquots of $20 \mu \mathrm{L}$ PCR products of the first exon in the Nanog gene were digested with $10 \mathrm{U} \mathrm{MvaI}$ at $37^{\circ} \mathrm{C}$ for $6-8 \mathrm{~h}$. The digested products were detected by $2.5-3.5 \%$ agarose gel (Lan et al., 2007). Meanwhile, aliquots of $20 \mu \mathrm{L}$ PCR products of exon 4 in the Nanog gene were digested with $10 \mathrm{U} \mathrm{MboI}$ at $37^{\circ} \mathrm{C}$ for $6-8 \mathrm{~h}$. The digested products were detected by $2.5-3.5 \%$ agarose gel (Lan et al., 2007). 

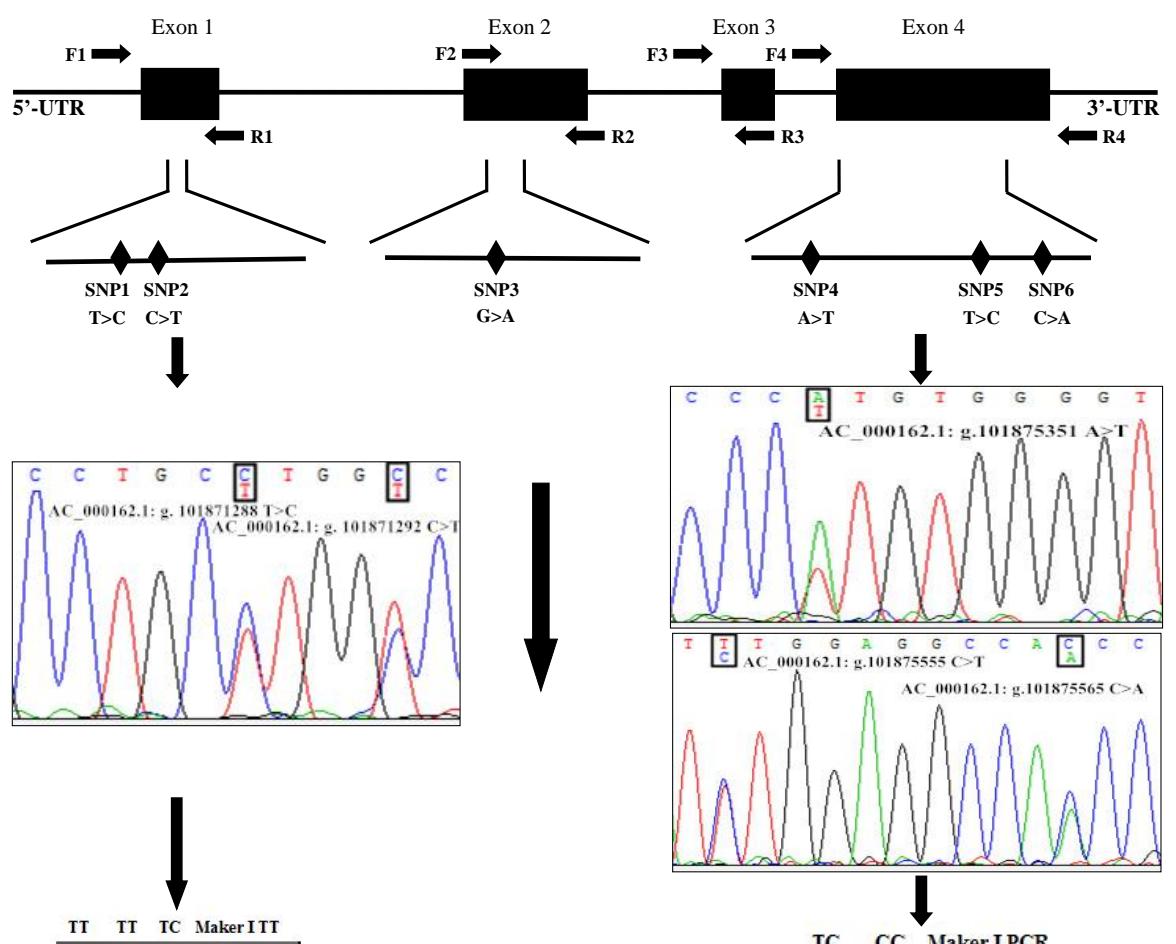

TT TT TC MakerITT
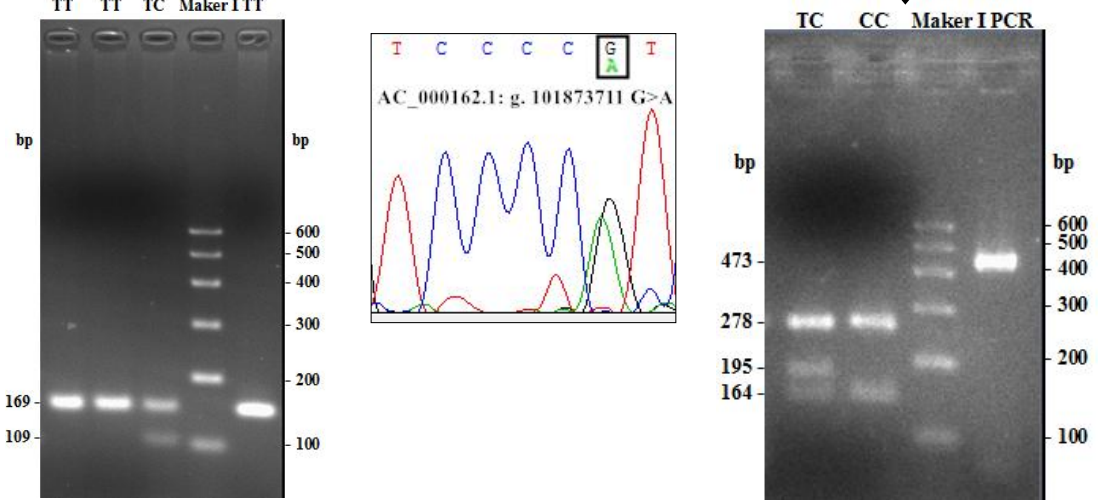

Figure 1. Sequencing of six SNPs and electrophoretograms of SNP1 and SNP5. Note: electrophoresis images show PCR-RFLP on SNP1 and SNP5. At SNP1, TT had $169 \mathrm{bp}$ and TC had $169 \mathrm{bp}$ and $109 \mathrm{bp}$. At SNP5, CC had 278 + $164 \mathrm{bp}$ and TC had $278+195+164 \mathrm{bp}$; total length of the fourth exon: $473 \mathrm{bp}$.

Table 2. Genotypes of different mutations corresponding to PCR-SSCP types in cattle

\begin{tabular}{llll}
\hline Fragments & Variation positions & SNP types & Descriptions \\
\hline P1 & g.101871288 T $>$ C (Exon1_35) & SNP1 & 12Leu/Pro, missense mutation \\
P1 & g.101871292 C $>$ T (Exon1_39) & SNP2 & 13Gly/Gly, synonymous mutation \\
P2 & g.101873711 G $>$ A (Exon2_86) & SNP3 & 74Pro/Pro, synonymous mutation \\
P4 & g.101875351 A $>$ T (Exon4_79) & SNP4 & 189Met/Leu, missense mutation \\
P4 & g.101875555 C $>$ T (Exon4_283) & SNP5 & 257Leu/Leu, synonymous mutation \\
P4 & g.101875565 C $>$ A (Exon4_293) & SNP6 & 260Thr/Asn, missense mutation \\
\hline
\end{tabular}

Note: descriptions refer to NM_001025344.1 and NP_001020515.1. 
Table 3. Genotypic frequencies, allelic frequencies, HWE, and population parameters of the Nanog gene in Chinese cattle.

\begin{tabular}{|c|c|c|c|c|c|c|c|c|c|c|c|c|}
\hline Loci & Breeds & $N$ & $\mathrm{TT}$ & $\mathrm{TC}$ & $\mathrm{CC}$ & $\mathrm{T}$ & $\mathrm{C}$ & $P$ & Ho & $\mathrm{He}$ & $\mathrm{Ne}$ & PIC \\
\hline \multirow[t]{6}{*}{ SNP1 } & NY & 247 & 0.996 & 0.004 & 0 & 0.998 & 0.002 & $P>0.05$ & 0.996 & 0.004 & 1.004 & 0.004 \\
\hline & QC & 144 & 1.000 & 0 & 0 & 1.000 & 0 & $P>0.05$ & 1.000 & 0 & 1.000 & 0 \\
\hline & $\mathrm{JX}$ & 269 & 0.970 & 0.030 & 0 & 0.985 & 0.015 & $P>0.05$ & 0.971 & 0.029 & 1.030 & 0.029 \\
\hline & $\mathrm{JN}$ & 28 & 1.000 & 0 & 0 & 1.000 & 0 & $P>0.05$ & 1.000 & 0 & 1.000 & 0 \\
\hline & Angus & 47 & 1.000 & 0 & 0 & 1.000 & 0 & $P>0.05$ & 1.000 & 0 & 1.000 & 0 \\
\hline & Holstein & 61 & 1.000 & 0 & 0 & 1.000 & 0 & $P>0.05$ & 1.000 & 0 & 1.000 & 0 \\
\hline Loci & Breeds & $N$ & $\mathrm{CC}$ & CT & $\mathrm{TT}$ & $\mathrm{C}$ & $\mathrm{T}$ & $P$ & Ho & $\mathrm{He}$ & $\mathrm{Ne}$ & PIC \\
\hline \multirow[t]{6}{*}{ SNP2 } & NY & 247 & 0.996 & 0.004 & 0 & 0.998 & 0.002 & $P>0.05$ & 0.996 & 0.004 & 1.004 & 0.004 \\
\hline & QC & 144 & 1.000 & 0 & 0 & 1.000 & 0 & $P>0.05$ & 1.000 & 0 & 1.000 & 0 \\
\hline & $\mathrm{JX}$ & 269 & 0.970 & 0.030 & 0 & 0.985 & 0.015 & $P>0.05$ & 0.971 & 0.029 & 1.030 & 0.029 \\
\hline & $\mathrm{JN}$ & 28 & 1.000 & 0 & 0 & 1.000 & 0 & $P>0.05$ & 1.000 & 0 & 1.000 & 0 \\
\hline & Angus & 47 & 1.000 & 0 & 0 & 1.000 & 0 & $P>0.05$ & 1.000 & 0 & 1.000 & 0 \\
\hline & Holstein & 61 & 1.000 & 0 & 0 & 1.000 & 0 & $P>0.05$ & 1.000 & 0 & 1.000 & 0 \\
\hline Loci & Breeds & $N$ & GG & GA & $\mathrm{AA}$ & $\mathrm{G}$ & A & $P$ & Ho & $\mathrm{He}$ & $\mathrm{Ne}$ & PIC \\
\hline \multirow[t]{6}{*}{ SNP3 } & NY & 151 & 0.616 & 0 & 0.384 & 0.616 & 0.384 & $P<0.01$ & 0.527 & 0.473 & 1.898 & 0.361 \\
\hline & QC & - & - & - & - & - & - & - & - & - & - & - \\
\hline & $\mathrm{JX}$ & 74 & 0.689 & 0.311 & 0 & 0.845 & 0.155 & $P<0.05$ & 0.737 & 0.263 & 1.356 & 0.228 \\
\hline & $\mathrm{JN}$ & - & - & - & - & - & - & - & - & - & - & - \\
\hline & Angus & - & - & - & - & - & - & - & - & - & - & - \\
\hline & Holstein & 61 & 1.000 & 0 & 0 & 1.000 & 0 & $P>0.05$ & 1.000 & 0 & 1.000 & 0.000 \\
\hline Loci & Breeds & $N$ & AA & AT & $\mathrm{TT}$ & A & $\mathrm{T}$ & $P$ & Ho & $\mathrm{He}$ & $\mathrm{Ne}$ & PIC \\
\hline \multirow[t]{6}{*}{ SNP4 } & NY & 101 & 0.792 & 0.208 & 0 & 0.896 & 0.104 & $P>0.05$ & 0.814 & 0.186 & 1.229 & 0.169 \\
\hline & QC & 140 & 0.564 & 0.436 & 0 & 0.782 & 0.218 & $P<0.01$ & 0.659 & 0.341 & 1.517 & 0.283 \\
\hline & $\mathrm{JX}$ & 116 & 0.940 & 0.060 & 0 & 0.970 & 0.030 & $P>0.05$ & 0.941 & 0.059 & 1.062 & 0.057 \\
\hline & $\mathrm{JN}$ & - & - & - & - & - & - & - & - & - & - & - \\
\hline & Angus & - & - & - & - & - & - & - & - & - & - & - \\
\hline & Holstein & - & - & - & - & - & - & - & - & - & - & - \\
\hline Loci & Breeds & $N$ & $\mathrm{CC}$ & $\mathrm{CT}$ & $\mathrm{TT}$ & $\mathrm{C}$ & $\mathrm{T}$ & $P$ & Ho & $\mathrm{He}$ & $\mathrm{Ne}$ & PIC \\
\hline \multirow[t]{6}{*}{ SNP5 } & $\mathrm{NY}$ & 101 & 0.941 & 0.059 & 0 & 0.970 & 0.030 & $P>0.05$ & 0.942 & 0.058 & 1.061 & 0.056 \\
\hline & QC & 140 & 0.450 & 0.550 & 0 & 0.725 & 0.275 & $P<0.01$ & 0.601 & 0.399 & 1.663 & 0.319 \\
\hline & $\mathrm{JX}$ & 116 & 0.276 & 0.724 & 0 & 0.638 & 0.362 & $P<0.01$ & 0.538 & 0.462 & 1.859 & 0.355 \\
\hline & $\mathrm{JN}$ & - & - & - & - & - & - & - & - & - & - & - \\
\hline & Angus & - & - & - & - & - & - & - & - & - & - & - \\
\hline & Holstein & - & - & - & - & - & - & - & - & - & - & - \\
\hline Loci & Breeds & $N$ & $\mathrm{CC}$ & $\mathrm{CA}$ & $\mathrm{AA}$ & $\mathrm{C}$ & A & $P$ & Ho & $\mathrm{He}$ & $\mathrm{Ne}$ & PIC \\
\hline \multirow[t]{6}{*}{ SNP6 } & NY & 101 & 0.941 & 0.059 & 0 & 0.970 & 0.030 & $P>0.05$ & 0.942 & 0.058 & 1.061 & 0.056 \\
\hline & QC & 140 & 0.421 & 0.550 & 0.029 & 0.696 & 0.304 & $P<0.01$ & 0.577 & 0.423 & 1.733 & 0.333 \\
\hline & $\mathrm{JX}$ & 116 & 0.267 & 0.724 & 0.009 & 0.629 & 0.371 & $P<0.01$ & 0.533 & 0.467 & 1.875 & 0.358 \\
\hline & $\mathrm{JN}$ & - & - & - & - & - & - & - & - & - & - & - \\
\hline & Angus & - & - & - & - & - & - & - & - & - & - & - \\
\hline & Holstein & - & - & - & - & - & - & - & - & - & - & - \\
\hline
\end{tabular}

Note: HWE - Hardy-Weinberg equilibrium; Ho - homozygosity; He - heterozygosity; $\mathrm{Ne}$ - effective allele numbers; PIC - polymorphism information content. 
Table 4. Haplotypes and their frequencies of six SNPs in Nanyang cattle and Jiaxian cattle.

\begin{tabular}{lllll}
\hline HAP (haplotype) & Hap. seq. & Total (no./freq.) & \multicolumn{2}{c}{ Breeds (no./freq.) } \\
\cline { 4 - 5 } & & & NY & JX \\
\hline Hap1 & T C A A C C & $80.090 / 0.260$ & $66.000 / 0.379$ & $12.510 / 0.093$ \\
Hap2 & T C A A T A & $11.910 / 0.039$ & $8.000 / 0.046$ & $5.490 / 0.041$ \\
Hap3 & T C A T C C & $6.000 / 0.019$ & $6.000 / 0.034$ & $0 / 0$ \\
Hap4 & T C G A C C & $155.910 / 0.506$ & $79.000 / 0.454$ & $78.490 / 0.586$ \\
Hap5 & T C G A T A & $42.090 / 0.137$ & $6.000 / 0.034$ & $34.510 / 0.258$ \\
Hap6 & T C G T C C & $11.000 / 0.036$ & $9.000 / 0.052$ & $2.000 / 0.015$ \\
Hap7 & C T G A T A & $1.000 / 0.003$ & $0 / 0$ & $1.000 / 0.007$ \\
\hline
\end{tabular}

\subsection{Statistical analysis}

Genotypic and allelic frequencies were calculated by PopGene version 3.2 (Yeh et al., 2000). The Hardy-Weinberg equilibrium (HWE) was analyzed based on a predetermined value of the test statistic (Emigh, 1980). Linkage disequilibrium was performed by the SHEsis online platform (http: //analysis.bio-X.cn) (Shi et al., 2005; Li et al., 2009). Population parameters, including gene heterozygosity $(\mathrm{He})$, gene homozygosity (Ho), effective allele numbers $(\mathrm{Ne})$, and polymorphism information content (PIC), were calculated according to Nei's method (Nei and Roychoudhury, 1974). Distribution differences for genotypic and allelic frequencies among different breeds were analyzed using the $\chi^{2}$ test. The associations between genotypes and growth traits of cattle were analyzed using the statistical software SPSS (Version 22.0, International Business Machines (IBM) Corporation, New York, USA; Pan et al., 2013). The linear model was as follow: $Y_{i j k}=\mu+A_{i}+G_{j}+e_{i j k}$, where $Y_{i j k}$ represents the observation of the body measurement traits, $\mu$ the overall mean of each trait, $A_{i}$ the fixed effect of age, $G_{j}$ the fixed effect of genotype or combined genotype, and $e_{i j k}$ the random residual error (Chen et al., 2016; Zhang et al., 2015). The effect of genotype was a significant variation source, when the $P$ value for the difference was less than 0.05 between the least squares means for each genotype (Lan et al., 2013; Zhao et al., 2013).

\section{Results}

\subsection{Genetic variant identification of the Nanog gene}

Through the experiment, we found two mutations in exon1 (AC_000162.1: g.101871288T >C, g.101871292C > T), one mutation in exon2 (AC_000162.1: g.101873711G $>$ A), and three mutations in exon4 (AC_000162.1: g.101875351A $>$ T, g. $101875555 \mathrm{C}>\mathrm{T}$, and g. $101875565 \mathrm{C}>\mathrm{A})$ in the Nanog gene by DNA sequencing and PCR-SSCP, named SNP1-6, respectively (Fig. 1). SNP1, SNP4, and SNP6 were missense mutations corresponding to 12Leu $>$ Pro, 189Met $>$ Leu, and $260 \mathrm{Thr}>$ Asn, respectively (Table 2). We performed PCRRFLP on SNP1 and SNP5 using MvaI and MboI, respec- tively, and did DNA sequencing on other SNPs (Fig. 1). Frequencies of alleles and genotypes, $\mathrm{He}, \mathrm{Ho}, \mathrm{Ne}$, and PIC in six cattle breeds are listed in Table 3. The minor allelic frequencies among six breeds of SNP1 and SNP2 ranged from 0.002 to 0.015 ; those of SNP3 ranged from 0.000 to 0.384 , those of SNP4 from 0.030 to 0.218 , those of SNP5 from 0.030 to 0.362 , and those of SNP6 from 0.030 to 0.371 . The $\chi^{2}$ test showed that SNP1 and SNP2 of all cattle breeds were in Hardy-Weinberg equilibrium (HWE), yet other polymorphisms in several cattle breeds were not in HWE and are shown in Table 3.

\subsection{Haplotype analysis and linkage disequilibrium}

Seven haplotypes were analyzed in NY and JX cattle breeds, namely Hap1 (TCAACC), Hap2 (TCAATA), Hap3 (TCATCC), Hap4 (TCGACC), Hap5 (TCGATA), Hap6 (TCGTCC), and Hap7 (CTGATA). Frequencies of seven haplotypes of NY were 0.379 (Hap1), 0.046 (Hap2), 0.034 (Hap3), 0.454 (Hap4), 0.034 (Hap5), 0.052 (Hap6), and 0 (Hap7). Haplotype frequencies among JX were 0.093 (Hap1), 0.041 (Hap2), 0 (Hap3), 0.586 (Hap4), 0.258 (Hap5), 0.015 (Hap6), and 0.007 (Hap7). Among them, the frequency of Hap4 was the highest in JX and NY (Table 4). Viewing the linkage disequilibrium of six SNPs (Table 5, Fig. 2), SNP5 and SNP6 had strong linkage $\left(r^{2}>0.33\right)$ in both NY and JX, and an LD (linkage disequilibrium) between SNP1 and SNP2 was detected in JX.

\subsection{Association analysis}

SPSS statistics revealed that three mutations (SNP3, SNP4, and SNP5) showed a significant association with the growth traits in NY and JX. At the SNP3 locus, individuals with a GG genotype had a longer body slanting length and chest circumference than those with an AA genotype in 6-month-old NY $(P<0.05)$. NY with an AA genotype at SNP4 showed a longer body length and better hucklebone width than AT heterozygotes at 6 months old $(P<0.05)$. JX that were CC homozygous at SNP5 had greater body height $(P<0.05)$ and a significantly greater cannon circumference $(P<0.01)$ than CT heterozygotes (Table 6). The combined genotype of 


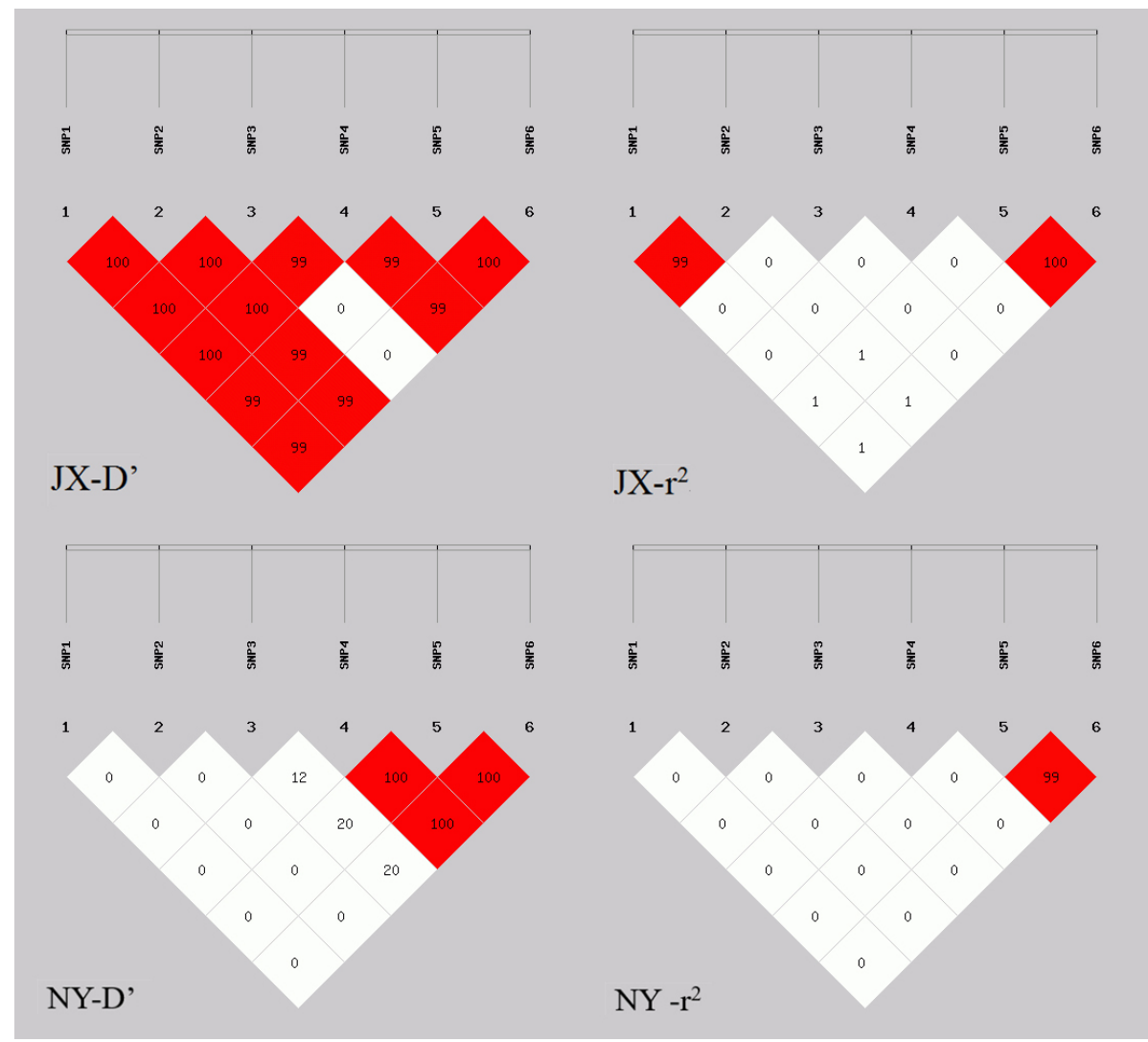

Figure 2. Linkage disequilibrium of Nanog gene polymorphisms in Jiaxian and Nanyang cattle. White squares show weak linkage and red squares show strong linkage.

Table 5. Linkage disequilibrium tests for Nanyang cattle and Jiaxian cattle.

\begin{tabular}{llllllll}
\hline \multicolumn{7}{l}{ NY breed: $\mathrm{D}^{\prime}$ and $r^{2}$ : SNP1/SNP2/SNP3/SNP4/SNP5/SNP6 } \\
\hline- & SNP1 & SNP2 & SNP3 & SNP4 & SNP5 & SNP6 & D $^{\prime}$ \\
SNP6 & - & 0.000 & 0.000 & 0.000 & 0.000 & 0.000 & SNP1 \\
SNP5 & 1.000 & - & 0.000 & 0.000 & 0.000 & 0.000 & SNP2 \\
SNP4 & 0.008 & 0.008 & - & 0.130 & 0.207 & 0.207 & SNP3 \\
SNP3 & 0.004 & 0.004 & 0.001 & - & 1.000 & 1.000 & SNP4 \\
SNP2 & 0.000 & 0.000 & 0.000 & 0.000 & - & 1.000 & SNP5 \\
SNP1 & 0.000 & 0.000 & 0.000 & 0.000 & 0.000 & - & SNP6 \\
$r^{2}$ & SNP6 & SNP5 & SNP4 & SNP3 & SNP2 & SNP1 & - \\
\hline JX breed: D' and $r^{2}:$ SNP1/SNP2/SNP3/SNP4/SNP5/SNP6 & \\
\hline- & SNP1 & SNP2 & SNP3 & SNP4 & SNP5 & SNP6 & $\mathrm{D}^{\prime}$ \\
SNP6 & - & 1.000 & 1.000 & 1.000 & 0.996 & 0.996 & SNP1 \\
SNP5 & 1.000 & - & 1.000 & 1.000 & 0.996 & 0.996 & SNP2 \\
SNP4 & 0.007 & 0.007 & - & 1.000 & 0.002 & 0.002 & SNP3 \\
SNP3 & 0.000 & 0.000 & 0.002 & - & 1.000 & 1.000 & SNP4 \\
SNP2 & 0.017 & 0.017 & 0.000 & 0.001 & - & 1.000 & SNP5 \\
SNP1 & 0.017 & 0.017 & 0.000 & 0.001 & 1.000 & - & SNP6 \\
$r^{2}$ & SNP6 & SNP5 & SNP4 & SNP3 & SNP2 & SNP1 & - \\
\hline
\end{tabular}

Note: values of upper triangular show D' and values of lower triangular represent $r^{2}$.
Table 6. The characteristics of three mutations in the Nanog gene in cattle. The numbers in the "traits" column indicate age in months.

\begin{tabular}{|c|c|c|c|}
\hline \multirow[t]{2}{*}{ Traits (NY) } & \multicolumn{2}{|c|}{ Genotypes (SNP3 G>A) } & \multirow[t]{2}{*}{$P$} \\
\hline & GG & AA & \\
\hline BSL-6 (cm) & $106.79 \pm 0.81^{\mathrm{a}}$ & $103.25 \pm 1.39^{b}$ & 0.022 \\
\hline $\mathrm{CC}-6(\mathrm{~cm})$ & $130.81 \pm 1.17^{\mathrm{a}}$ & $126.38 \pm 1.62^{b}$ & 0.028 \\
\hline \multirow[t]{2}{*}{ Traits (NY) } & \multicolumn{2}{|c|}{ Genotypes (SNP4 A>T) } & $P$ \\
\hline & AA & AT & \\
\hline $\mathrm{BH}-6(\mathrm{~cm})$ & $106.29 \pm 0.75^{\mathrm{a}}$ & $102.30 \pm 1.58^{b}$ & 0.031 \\
\hline $\mathrm{HW}-18(\mathrm{~cm})$ & $23.30 \pm 0.27^{\mathrm{a}}$ & $21.95 \pm 0.36^{\mathrm{b}}$ & 0.035 \\
\hline \multirow[t]{2}{*}{ Traits (JX) } & \multicolumn{2}{|c|}{ Genotypes (SNP5 C>T) } & $P$ \\
\hline & $\mathrm{CC}$ & CT & \\
\hline $\mathrm{BH}(\mathrm{cm})$ & $126.69 \pm 0.75^{a}$ & $124.31 \pm 0.60^{b}$ & 0.028 \\
\hline $\mathrm{CaC}(\mathrm{cm})$ & $17.71 \pm 0.15^{\mathrm{A}}$ & $16.98 \pm 0.13^{\mathrm{B}}$ & 0.002 \\
\hline
\end{tabular}

Note: ${ }^{\mathrm{a}, \mathrm{b}}$ Values with different superscripts in the same row differ significantly at $P<0.05$. A, B Values with different superscripts in the same row differ significantly at $P<0.01$. BSL - body slanting length; $\mathrm{CC}-$ chest circumference; $\mathrm{BH}$ - body height; $\mathrm{HW}$ - hucklebone width; $\mathrm{CaC}$ - cannon circumference. 
Table 7. Relationship between the combined genotypes of two loci and phenotypes in Nanyang cattle. The numbers in the "traits" column indicate age in months.

\begin{tabular}{llllll}
\hline \multirow{2}{*}{ Traits } & \multicolumn{3}{c}{ SNP3-SNP4 } & $P$ \\
\cline { 2 - 5 } & GG-AA (31) & GG-AT (5) & AA-AA (16) & AA-AT (5) & \\
\hline BH-6 (cm) & $107.81 \pm 0.75^{\mathrm{a}}$ & $102.60 \pm 2.34^{\mathrm{b}}$ & $103.94 \pm 1.54^{\mathrm{b}}$ & $102.00 \pm 2.39^{\mathrm{b}}$ & 0.011 \\
BSL-6 (cm) & $107.71 \pm 0.91^{\mathrm{a}}$ & $103.20 \pm 3.25^{\mathrm{ab}}$ & $103.38 \pm 1.84^{\mathrm{b}}$ & $101.60 \pm 2.38^{\mathrm{b}}$ & 0.038 \\
CC-18 (cm) & $157.45 \pm 1.26^{\mathrm{a}}$ & $148.20 \pm 4.34^{\mathrm{b}}$ & $154.06 \pm 1.57^{\mathrm{ab}}$ & $153.80 \pm 2.60^{\mathrm{ab}}$ & 0.041 \\
\hline
\end{tabular}

Note: means \pm standard errors of measurement traits of Nanyang cattle with combined genotype (SNP3-SNP4). a, b Values with different superscripts in the same row differ significantly at $P<0.05$. BH - body height; BSL - body slanting length; CC - chest circumference.

SNP3-GG and SNP4-AA was found to have a positive effect on body height and body slanting length in 6-month-old NY. Moreover, the combined genotype GG-AA had better chest circumference in 18-month-old NY (Table 7).

\section{Discussion}

The familiar function of Nanog is that it regulates the pluripotency of ESCs and induces pluripotent stem cell formation (Komatsu et al., 2015). Previous reports showed that iPSC-related Klf4 affected adipogenesis through interacting with other genes. Equally, Klf7 also affected bovine growth traits and the quality of milk (Ma et al., 2011). The examples above were evidence to suppose that iPSC-related Nanog may influence the phenotypes. Therefore, we checked the effects of six SNPs in the Nanog gene on body measurement traits in cattle in this study.

We found six novel exonic SNPs in four exons of the Nanog gene. Through the $\chi^{2}$ test, SNP1 and SNP2 in all cattle breeds were in HWE; SNP1 and SNP2 did not affect growth traits, and artificial selection was not performed among all breeds. SNP3, SNP4, SNP5, and SNP6 were not in HWE in different cattle breeds. The explanation was that artificial selection was performed to acquire better characteristics, and the genetic backgrounds of breeds were different. Although SNP6 was not associated with growth traits, SNP5 and SNP6 were in a strong LD, leading to both of them being selected in artificial selection. The common Hap4 had the highest frequency in both NY and JX, perhaps because Hap4 was present in these breeds for a long time (Zhang et al., 2015). The frequencies of other haplotypes were different, which may be due to variety distinctiveness (Zhang et al., 2015). SNP5 and SNP6 were in a strong LD in NY and JX, and SNP1 and SNP2 showed strong linkage only in JX. NY and JX belong to special Chinese breeds, but they were raised in different environments, which caused their different genetic backgrounds and heritability. SNP4 caused 189Met to be changed into 189Leu so as to affect measurement traits in NY. SNP3 and SNP5 were synonymous mutations, not changing the sequence of amino acids. However, the growth traits of individuals with SNP3 or SNP5 were better than those of the wild type (Table 2). Studies have reported that synonymous codon influenced nucleic acid stability, protein levels, structure, and function without altering the amino acid sequence (Bali and Bebok, 2015). The combined genotype of SNP3-GG and SNP4-AA had a positive effect on body height, body slanting length, and chest circumference. Probably, 6-month-old NY with SNP3-GG and SNP4-AA could be selected to obtain better body height and body slanting length; 18-month-old NY could be selected for better chest circumference. Both SNP3 and SNP4 affected the growth traits in this research.

The association testing showed that the Nanog gene had a remarkable effect on growth traits. As far as we know, we are the first to research the relationship between the Nanog gene and growth characteristics. For a better comprehension of this study, the possible explanations are listed as follows:

1. The SNP4 was a missense mutation: 189 Met $>$ Leu. The missense mutation with the amino acid change could affect protein structure, resulting in a loss of normal function.

2. Nanog combines with the binding site of the GDF3 promoter and activates the expression of GDF3 in humans, which belongs to TGF- $\beta$ family and controls the bone morphogenic protein (McPherron and Lee, 1993; Park et al., 2012). GDF3 is also expressed in spleen, thymus, fat, and bone marrow (Hexige et al., 2005) and increases the adipose accumulation in a high-fat diet in mice, via the receptor ALK7 and ALK4 expressing in adipose tissue (Andersson et al., 2008). We speculated that the mutations of the Nanog gene in the coding with a protein structure change possibly regulated GDF3 expression, further impacting growth traits in cattle.

3. Nanog also inhibits the transcriptional effectors of both the bone morphogenetic protein and NF-kappa B pathways in ESCs ( $\mathrm{Li}$ et al., 2016). Maybe the expression of Nanog was changed or reduced gradually with age, removing the inhibition of bone morphogenetic protein and NF-kappa B pathways in calves. 
4. GLI1 and GLI3 were able to bind to Nanog. The presence of Nanog inhibited GLI transcription, therefore inhibiting Hedgehog signaling that regulated the homeostasis of several types of adult tissue (Li et al., 2016). Possibly, Nanog was also changed or reduced and removed the inhibition of GLI1.

MAS would develop and improve cattle products. Analyzing novel nucleotide variations of the candidate genes and detecting their associations with economic traits are significant for cattle breeding and genetics (Zhang et al., 2015). Novel SNPs of Nanog have benefits for implementing MAS in genetics and the breeding of cattle. The material mechanisms of Nanog acting on genes and signal paths are unclear and need to be explored further.

\section{Conclusions}

To summarize, six novel genetic variations (SNP1-6) were found in this study. Among these, SNP3, SNP4, and SNP5 were associated with growth traits in NY and JX which were beneficial to cattle breeding and genetics through MAS.

\section{Data availability}

The original data are available upon request to the corresponding author. 
Appendix A: Abbreviations

GDF3 growth and differentiation factor 3

Klf4 Krüppel-like factor 4

TGF- $\beta \quad$ transforming growth factor $\beta$

iPSCs induced pluripotent stem cells

SNP single nucleotide polymorphism

MAS marker-assisted selection

bp base pair

SPSS statistical product and service solutions

PCR polymerase chain reaction

SSCP single-stranded conformational polymorphism

PCR-RFLP polymerase chain reaction-restriction fragment length polymorphism

HWE Hardy-Weinberg equilibrium

Ho homozygosity

$\mathrm{He} \quad$ heterozygosity

$\mathrm{Ne} \quad$ effective allele numbers

PIC polymorphism information content

LD linkage disequilibrium

QC Qinchuan cattle

NY Nanyang cattle

JN Jinnan cattle

JX Jiaxian cattle

BH body height

BSL body slanting length

CC chest circumference

HW hucklebone width

$\mathrm{CaC}$ cannon circumference 


\section{Conflict of interest}

All authors have no conflict of interest with any financial organization regarding the material discussed in the manuscript.

Author contributions. Meng Zhang conceived the study and wrote the paper. Chuanying Pan performed the experiments. Qin Lin and Shenrong $\mathrm{Hu}$ analyzed the data; Ruihua Dang did statistical analysis; Chuzhao Lei and Hong Chen collected the samples; Xianyong Lan edited and reviewed the manuscript.

Acknowledgements. This work was supported by the Science and Technology Overall Project of Shaanxi Province (No.2014KTZB02-02-02-02), Bio-breeding Capacity-building and Industry Specific Projects from the National Development and Reform Commission (2014-2573), the Specific Projects of Science and Technology in Henan Province (141100110200), and the Program of National Beef Cattle and Yak Industrial Technology System (CARS-38).

Edited by: S. Maak

Reviewed by: S. Mekchay and three anonymous referees

\section{References}

Andersson, O., Korach-Andre, M., Reissmann, E., Ibáñez, C. F., and Bertolino, P.: Growth/differentiation factor 3 signals through ALK7 and regulates accumulation of adipose tissue and dietinduced obesity, P. Natl. Acad. Sci. USA, 105, 7252-7256, 2008.

Bali, V. and Bebok, Z.: Decoding mechanisms by which silent codon changes influence protein biogenesis and function, Int. J. Biochem. Cell B., 64, 58-74, 2015.

Cervantes-Camacho, C., Beltrán-Langarica, A., Ochoa-Uribe, A. K., Marsch-Moreno, M., Ayala-Sumuano, J. T., Velez-delValle, C., and Kuri-Harcuch, W.: The transient expression of Klf4 and Klf5 during adipogenesis depends on GSK3 $\beta$ activity, Adipocyte, 4, 248-255, 2015.

Chen, R., Yu, S., Ren, F., Lv, X. Y., and Pan, C. Y.: Detection of one large insertion/deletion (indel) and two novel SNPs within the SPEF2 gene and their associations with male piglet reproduction traits, Arch. Anim. Breed., 59, 275-283, doi:10.5194/aab59-275-2016, 2016.

Clark, A. T., Rodriguez, R. T., Bodnar, M. S., Abeyta, M. J., Cedars, M. I., Turek, P. J., Firpo, M. T., and Reijo Pera, R. A.: Human STELLAR, NANOG, and GDF3 genes are expressed in pluripotent cells and map to chromosome 12p13, a hotspot for teratocarcinoma, Stem Cells, 22, 169-179, 2004.

Emigh, T. H.: A Comparison of Tests for Hardy-Weinberg Equilibrium, Biometrics, 36, 627-642, 1980.

Hexige, S., Guo, J. H., Ma, L. X., Sun, Y., Liu, X. H., Ma, L. J., Yan, X. M., Li, Z. J., and Yu, L.: Expression pattern of growth/differentiation factor 3 in human and murine cerebral cortex, hippocampus as well as cerebellum, Neurosci. Lett., 389, 83-87, 2005.
Komatsu, K. and Fujimori, T.: Multiple phases in regulation of Nanog expression during pre-implantation development, Dev. Growth Differ., 57, 648-656, 2015.

Lan, X. Y., Pan, C. Y., Chen, H., Zhang, C. L., Li, J. Y., Zhao, M., Lei, C. Z., Zhang, A. L., and Zhang, L.: An AluI PCR-RFLP detecting a silent allele at the goat POU1F1 locus and its association with production traits, Small Ruminant Res., 73, 8-12, 2007.

Lan, X. Y., Zhao, H. Y., Li, Z. J., Zhou, R., Jiang, X. W., Han, C. S., Pan, C. Y., Lei, C. Z., and Chen, H.: Exploring novel genetic variant of PITX1 gene and its effect on milk performance in dairy goats, J. Integr. Agricult., 12, 118-126, 2013.

Lei, L., Li, L., Du, F. L., Chen, C. H., Wang, H. Y., and Keefer, C. L.: Monitoring bovine fetal fibroblast reprogramming utilizing a bovine NANOG promoter-driven EGFP reporter system, Mol. Reprod. Dev., 80, 193-203, 2013.

Li, Q., Lex, R. K., Chung, H. W., Giovanetti, S. M., Ji, Z. C., Ji, H. C., Person, M. D., Kim, J., and Vokes, S. A.: NANOG binds to GLI proteins and represses Hedgehog-mediated transcription, J. Biol. Chem., 291, 7171-7182, 2016.

Li, Z. Q., Zhang, Z., He, Z. D., Tang, W., Li, T., Zeng, Z., He, L., and Shi, Y. Y.: A partition-ligation-combination-subdivision EM algorithm for haplotype inference with multiallelic markers: update of the SHEsis (http://analysis.bio-x.cn), Cell Res., 19, 519523, 2009.

Liang, G. Y. and Zhang, Y.: Genetic and epigenetic variations in iPSCs: potential causes and implications for application, Cell Stem Cell, 13, 149-159, 2013.

Ma, L., Qu, Y. J., Huai, Y. T., Li, Z. J., Wang, J., Lan, X. Y., Zhang, C. L., Wang, J. Q., and Chen, H.: Polymorphisms identification and associations of KLF7 gene with cattle growth traits, Livest. Sci., 135, 1-7, 2011.

McPherron, A. C. and Lee, S. J.: GDF-3 and GDF-9: two new members of the transforming growth factor-beta superfamily containing a novel pattern of cysteines, J. Biol. Chem., 268, 3444-3449, 1993.

Nei, M. and Roychoudhury, A. K.: Sampling variances of heterozygosity and genetic distance, Genetics, 76, 379-390, 1974.

Pan, C. Y., Lan, X. Y., Chen, H., Yang, D. Y., Hua, L. S., Yang, X. B., Lei, C. Z., Guo, Y. K., Zhang, B., Zhang, C. L., Kang, X. T., and Wang, X. Z.: A DdeI PCR-RFLP detecting a novel missense mutation of POU1F1 gene showed no effects on growth traits in cattle, Czech J. Anim. Sci., 53, 523-527, 2008.

Pan, C. Y., Wu, C. Y., Jia, W. C., Xu, Y., Hu, S. R., Lei, C. Z., Lan, X. Y., and Chen, H.: A critical functional missense mutation (H173R) in the bovine PROP1 gene significantly affects growth traits in cattle, Gene, 531, 398-402, 2013.

Park, S. W., Lim, H. Y., Do, H. J., Sung, B., Huh, S. H., Uhmc, S. J., Song, H., Chung, H. J., Kim, J. H., Kim, N. H., and Kim, J. H.: Regulation of human growth and differentiation factor 3 gene expression by NANOG in human embryonic carcinoma NCCIT cells, FEBS Lett., 586, 3529-3535, 2012.

Rodda, D. J., Chew, J. L., Lim, L. H., Loh, Y. H., Wang, B., and Ng, H. H.: Transcriptional regulation of nanog by OCT4 and SOX2, J. Biol. Chem., 280, 24731-24737, 2005.

Sambrook, J. and Russell, D. W.: Molecular cloning: a laboratory manual, 3rd Edn., Vol. 3, Cold Spring Harbor Laboratory Press, New York, 2001. 
Shi, T., Peng, W., Yan, J., Cai, H., Lan, X., Lei, C., Bai, Y., and Chen, H.: A novel 17 bp indel in the SMAD3 gene alters transcription level, contributing to phenotypic traits in Chinese cattle, Arch. Anim. Breed., 59, 151-157, doi:10.5194/aab-59-1512016, 2016.

Shi, Y. Y. and He, L.: SHEsis, a powerful software platform for analyses of linkage disequilibrium, haplotype construction, and genetic association at polymorphism loci, Cell Res., 15, 97-98, 2005.

Sumer, H., Liu, J., Malaver-Ortega, L. F., Lim, M. L., Khodadadi, K., and Verma, P. J.: NANOG is a key factor for induction of pluripotency in bovine adult fibroblasts, J. Anim. Sci., 89, 2708 2716, 2011.

Wang, W., Yang, Y., Meng, Y., and Shi, Y. G.: GDF-3 is an adipogenic cytokine under high fat dietary condition, Biochem. Bioph. Res. Co., 321, 1024-1031, 2004.
Yang, F., Zhang, J. L., Liu, Y. J., Cheng, D., and Wang, H. Y.: Structure and functional evaluation of porcine NANOG that is a single-exon gene and has two pseudogenes, Int. J. Biochem. Cell B., 59, 142-152, 2015.

Yeh, F. C., Yang, R., and Boyle, T.: POPGENE Version 3.1, Microsoft Window-based Freeware for Population Genetic Analysis, Edmonton, AB, Canada, University of Alberta, 1999.

Zhang, X. Y., Wu, X. F., Jia, W. C., Pan, C. Y., Li, X. C., Lei, C. Z., Chen, H., and Lan, X. Y.: Novel Nucleotide variations, haplotypes structure and associations with growth related traits of goat AT motif-binding factor (ATBF1) gene, Asian Austral. J. Anim., 10, 1394-1406, 2015.

Zhao, H. Y., Wu, X. F., Cai, H. F., Pan, C. Y., Lei, C. Z., Chen, H., and Lan, X. Y.: Genetic variants and effects on milk traits of the caprine paired-like homeodomain transcription factor 2 (PITX2) gene in dairy goats, Gene, 532, 203-210, 2013. 